\title{
Coronary Flow Reserve from Mouse to Man-from Mechanistic Understanding to Future Interventions
}

\author{
Li-Ming Gan • Johannes Wikström • Regina Fritsche-Danielson
}

Received: 21 May 2013 / Accepted: 1 July 2013 / Published online: 23 July 2013

(C) The Author(s) 2013. This article is published with open access at Springerlink.com

\begin{abstract}
Myocardial ischemia is recognized as an important mechanism increasing the risk for cardiovascular events in both symptomatic and asymptomatic patients. In addition to obstructive coronary diseases, systemic inflammation, macro- and microvascular function are additional important mechanisms contributing to the ischemic myocardium. Accumulating evidence indicates that coronary flow reserve (CFR) is a quantitative measurement of ischemia including integrated information on structure and function of the coronary artery at all levels. Not surprisingly, CFR has been shown to confer strong prognostic value for hard cardiovascular (CV) events in a number of relevant patient cohorts. Using high-resolution imaging, it is now possible to study coronary arteries from mouse to man. Therefore, CFR may be an important translational tool to risk-stratify patients and to perform both preclinical and clinical proof-of-concept studies before investing in large-scale outcome trials, thus improving the translational value for novel $\mathrm{CV}$ targets.
\end{abstract}

Keywords Coronary flow reserve $\cdot$ Ischemia .

Cardiovascular events $\cdot$ Risk-stratification $\cdot$ Cardiac catheterization $\cdot \mathrm{PET} \cdot \mathrm{CT} \cdot \mathrm{MRI} \cdot$ Transthoracic echocardiography · Color Doppler · Translational medicine . Microvascular function · Systemic inflammation · Ischemic myocardium

Associate Editor Angela Taylor oversaw the review of this article

L.-M. Gan

Department of Molecular and Clinical Medicine, Institute of

Medicine at Sahlgrenska Academy, University of Gothenburg and

Sahlgrenska University Hospital, Göteborg, Sweden

L.-M. Gan $(\bowtie) \cdot J$. Wikström $\cdot$ R. Fritsche-Danielson

CVMD Innovative Medicine Unit, AstraZeneca R\&D, Mölndal,

Sweden

e-mail: li-ming.gan@astrazeneca.com

\section{Introduction}

During the last decade, a decline in age-adjusted cardiovascular (CV) mortality has been observed [1]. Increasing public awareness as well as recent advancement in medical and surgical interventions are considered contributing factors to this positive trend. However, ischemic cardiovascular disease remains the number one killer in the westernized world and increasing prevalence of diabetes and obesity is believed to accelerate the global cardiovascular disease burden [2].

There is accumulating evidence indicating that myocardial ischemia is an important cause associated with residual $\mathrm{CV}$ risks among both symptomatic and asymptomatic CAD $[3,4]$. Indeed, transient ischemia could also lead to sudden death due to lethal arrhythmia [5-7]. In the setting of chronic stable ischemic heart disease, angiogram-guided percutaneous coronary intervention (PCI) has not been shown to deliver superior benefits compared to optimal medical treatment, while a fractional flow reserve (FFR)-guided approach, which measures the hemodynamic significance of stenosis, has begun to demonstrate promising results (FAME II) [8].

Acute myocardial infarction (MI) is considered an atherothrombotic event, which in turn is under the influence of three major triggers according to Virchow's triad: vessel injury either through plaque rupture or endothelial erosion, hypercoagulability and finally reduced and/or disturbed flow $[9,10]$. In the arterial system with normal blood flow velocity around $1 \mathrm{~m} / \mathrm{s}$, flow-stopping atherothrombosis is rare, while in the venous system with slow and occasionally stagnated flow, thrombosis may occur without atherosclerosis. In contrast to most other arteries, where flow occurs predominantly in systole, coronary perfusion is mainly a diastolic event. Also, the normal blood flow velocity in the epicardial coronary arteries is much lower than in for example: aorta and carotid arteries [11]. The unique anatomy and physiology of the coronary circulation require specialized 
physiological adaptations. Understanding the biology of the coronary vascular bed may help us to risk stratify patients as well as identify novel treatment regimes to combat coronary artery disease.

\section{Concept of Coronary Flow Reserve}

The concept of coronary flow reserve (CFR) was introduced to reflect the maximal oxygen delivery capacity during increasing demand. Since cardiomyocytes are capable of extracting oxygen with great efficiency already at rest, the only way of meeting increasing demand is to increase coronary blood flow $[11,12]$. At rest, there is a significant autoregulation in the coronary vascular bed which ensures sufficient blood supply to the cardiomyocytes under a wide range of perfusion pressure. Thus, resting coronary blood flow is mainly under control of tissue metabolic demand [13]. To test the maximum flow reserve capacity, the autoregulation must be uncoupled, which will create a linear relationship between perfusion pressure and flow. Thus, CFR is usually measured during either exercise challenge or pharmacological stimuli such as dobutamine and adenosine [14].

Hemodynamically significant coronary lesions are known to cause reduced CFR $[12,14]$. In the case of diffuse coronary artery atherosclerosis without angiogram-visible significant stenosis, CFR could be an objective tool to assess the hemodynamic significance, not necessarily reflected by distinct local stenosis. This has been comprehensively described by Dr. Gould et al., who pioneered the concept in humans [15]. However, impaired CFR could be due to many other pathological conditions, such as microvascular dysfunction in for example: diabetic patients [16]. Interestingly, the presence of thin cap fibroma in the coronary artery has been reported to be associated with impaired CFR, indicating an important but not completely surprising link between atherosclerotic lesion composition and downstream vascular function [17].

While FFR seems to be a fit-for-purpose tool to address hemodynamic consequences of focal lesions, CFR could be a measure of the entire coronary vascular functionality. Even though there is correlation between CFR and FFR, significant discrepancy between these two measures is evident, which may suggest that they indeed reflect distinct aspects of the coronary arteries [18]. This means that not all patients with impaired CFR would have any intervenable coronary lesions according to FFR, and that CFR will not necessarily be improved even following the best FFR-guided PCI procedure.

Even though myocardial perfusion scintigram (MPS) is considered the gold-standard for assessment of myocardial ischemia, the method relies on flow-redistribution during stress testing when a hemodynamically significant stenosis is present. In the case of balanced three vessel disease and microvascular dysfunction, MPS results are less reliable in term of identifying the high risk patient [19]. CFR as an objective quantitative tool, will assess the hemodynamic significance of angiographic moderate or ambiguous stenosis, as well as diagnose microvascular diseases (Fig. 1) [15].

\section{Methods to Assess CFR in Man}

Coronary flow reserve can be measured using many modalities. Thermodilution was one of the invasive techniques used to determine CFR in man [20]. Coronary flow velocity reserve (CFVR) can be measured using invasive Dopplerguide wires using, for example adenosine as a stress agent [21]. Recently, a combined FFR and CFVR catheter has been launched for simultaneous flow and pressure measurement [22].

Non-invasive techniques have been developed during the last two decades taking advantage of modern high-end imaging modalities. Positron emission tomography (PET) is now established as the gold standard for absolute coronary blood flow and flow reserve measurement. PET provides both ischemia evaluation as well as absolute flow quantification [23]. Various tracers can be used including those that do not require a full-scale cyclotron facility, for example: rubidium [24]. In combination with high-resolution computer tomography $(\mathrm{CT})$, this modality can provide both structural and functional information about ischemic heart disease [25]. Even though PET is an established approach to assess CFR, radiation exposure as well as high equipment and running cost limit its wide use. Contrast $\mathrm{CT}$ might be a new modality for perfusion imaging. This method is also associated with radiation although the level of radiation has decreased substantially with the latest generation CT [26]. Magnetic resonance imaging is a non-radioactive valuable method, capable of assessing CFR, but is relatively costly and time-consuming [27].

Myocardial contrast echocardiography is an inexpensive and non-radioactive method for measurement of CFR. When image quality is adequate, CFVR as well as CFR can be readily measured [28]. However, for accurate and reproducible quantification of CFVR and CFR, high-quality images are required both during rest and hyperemia allowing contrast intensity measurement to derive flow velocity as well as steady-state flow signals.

Transthoracic color Doppler echocardiography (TDECFR) has been successfully used to measure coronary blood flow velocity (CBFV) and CFVR [29]. With proper machine setting and skilled hands, the technique is non-radioactive and feasible in every echo-lab without need of contrast agent. Using this approach, success rate is greatest in the left anterior descending (LAD) coronary artery. In addition, right posterior descending coronary artery [30] as well as circumflex artery 


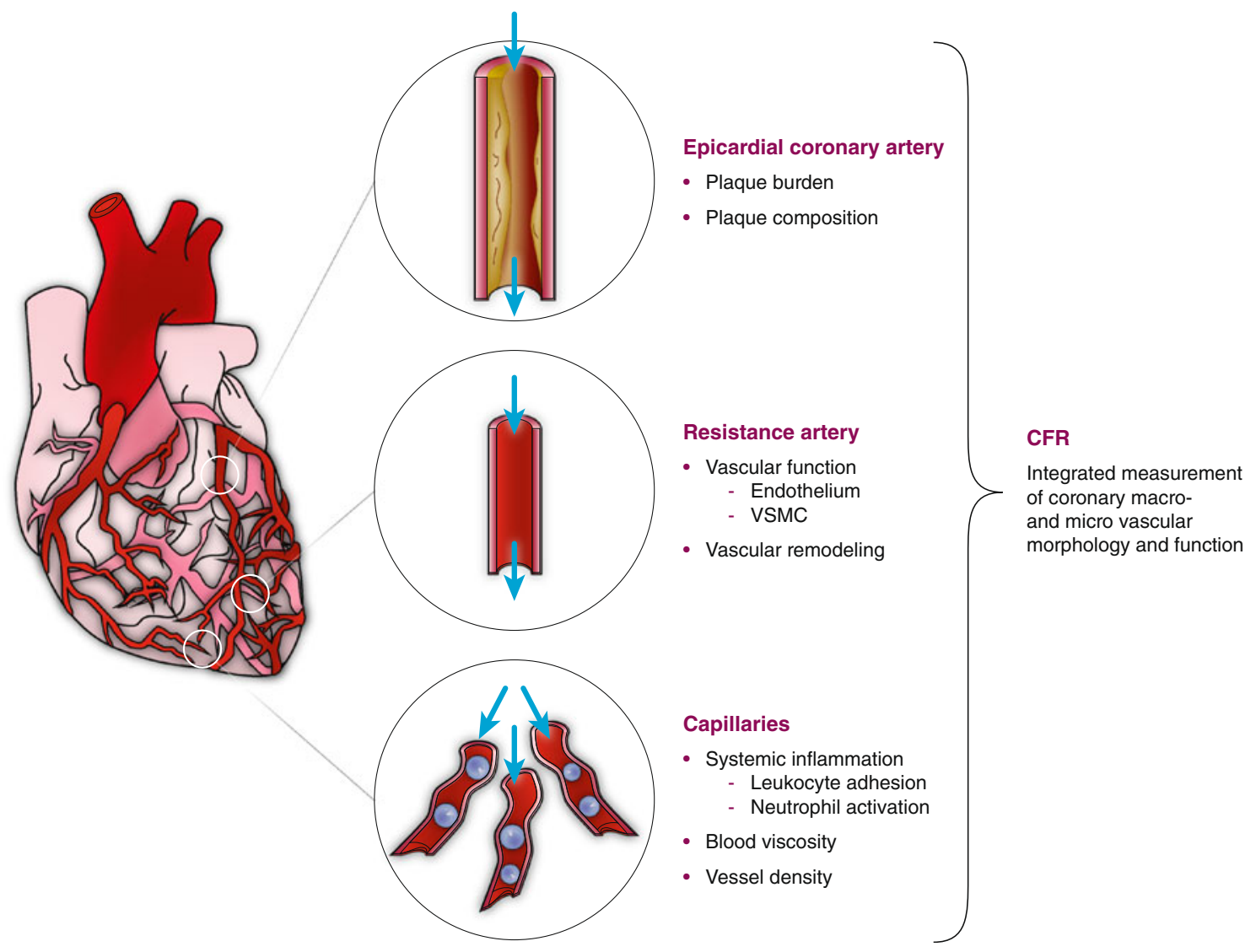

Fig. 1 CFR provides an integrative assessment of coronary vascular health at all levels of the vascular tree. Accumulating evidence suggests that myocardial ischemia is the net result of pathophysiological mechanisms within the epicardial vessels, resistance arteries and the capillaries. In addition to diffuse or obstructive epicardial atherosclerosis, vascular

(LCX) CFBV is measurable [31]. Accuracy of these approaches has been validated previously against invasive techniques [30]. Technically, for access to the distal LAD, only a small echo-window is needed compared to for example: left ventricle ejection fraction measurement using Simpson's rule, where a couple of cm echo-window is needed for good image quality. Thus, obesity is not an absolute hurdle for the success of this technique [32]. For real-life clinic use of this technique for diagnosis of ischemic heart disease including obstructive CAD and microvascular disease, dipyridamole-assisted TDECFR has been successfully applied on a routine basis in combination with wall motion analysis [33]. Using this approach, the high specificity of stress echo can be combined with the high sensitivity of CFR for diagnosis of ischemic heart disease in patients with suspect CAD.

For experimental purposes, LAD TDE-CFR has been used for risk prediction as well as documentation of intervention effects. Recently, our group showed excellent interand intra-day variability of CBFV in a randomized double blind clinical study [34]. During this study CBFV upon increasing doses of adenosine was measured repeatedly. To function and remodeling are important mechanisms contributing to overall myocardial perfusion. The microvasculature is influenced by systemic inflammation such as leukocyte adhesion and neutrophil activation with direct consequences on perfusion. Increased blood viscosity such as in hyperlipidemic patients, has also direct implications on capillary flow minimize environmental influences, all subjects stayed at the clinical trial unit the evening prior to the examination and received standardized meals etc. Thus, under controlled conditions, variability for CFBV measurement using this approach was satisfactorily low (Coefficient of variance for AUC for CBFV and adenosine doses $<1 \%$ ) (Fig. 2).

\section{Determinants of CFR in Man}

To further understand biological processes and the clinical relevance of CFR, numerous studies have been performed to relate CFR to cardiovascular biomarkers. These studies revealed that CFR indeed could serve as a composite physiological marker of systemic CV risk. Besides obstructive CAD, which is an obvious determinator of CFR [12, 14], impaired CFR has been reported in patients with dilated cardiomyopathy [35], as well as patients with diabetic vascular complications [36]. Further, myocardial capillary density has also been shown to determine CFR in patients with dilated cardiomyopathy [37]. 


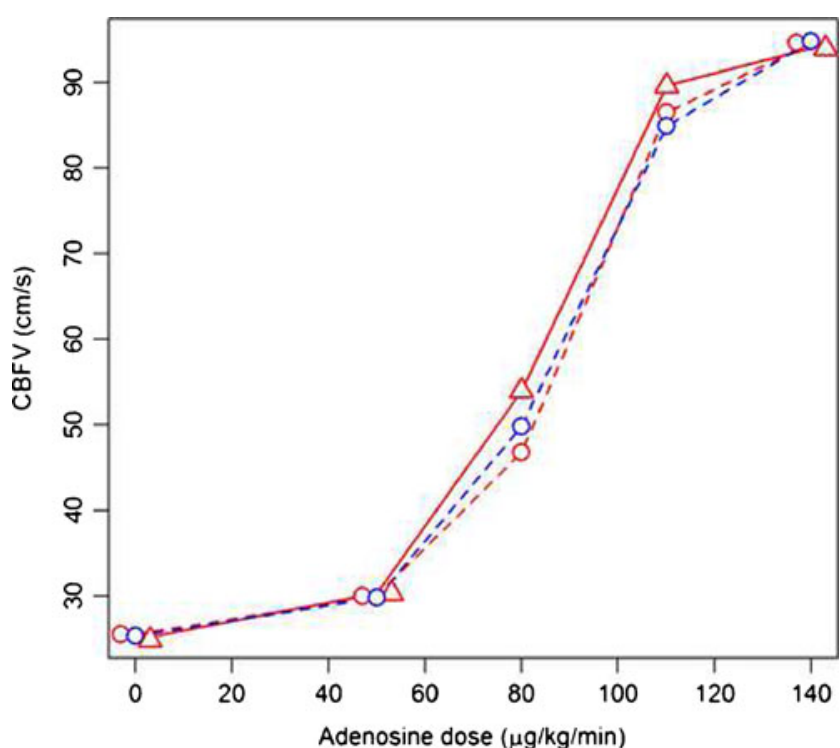

Fig. 2 Adenosine dose versus mean coronary blood flow velocity response pre-placebo (red dashed line, circle), post-placebo (red solid line, triangle) and pre-ticagrelor (blue dashed line, circle). Red dashed and red solid lines represent thus intra-day variability, whereas red dashed and blue dashed lines represent inter-day variability (adapted from [34])

CFR is rheologically associated with blood viscosity, which in turn is dependent on lipoprotein and fibrinogen levels. In familiar hypercholestoremic patients, CFR is related to LDL level and is improved after LDL apheresis, supporting the concept that increased blood viscosity due to extremely high LDL level can be a determinant of CFR [38].

CFR has also been shown to correlate to markers of low degree systemic inflammation, such as C-reactive protein [39] and neutrophil count [40]. Based on large-scale genetic association studies, IL-6 has recently been shown to be causally linked to CV outcome alongside LDL-regulating pathways [41]. Interestingly, a PET-CFR study conducted in twins showed that IL-6 indeed was a determinant of CFR in those asymptomatic subjects [42].

It is well-known that endothelium plays a central role in $\mathrm{CV}$ disease etiology and progression [43]. Even though CFR is measured using a non-endothelium dependent vasodilator, for example: adenosine, for achieving maximum hyperemic flow response, intact endothelial function is required. CFR has been shown to be associated with peripheral endothelial function both in chest pain patients and in healthy volunteers $[44,45]$ and direct inhibition of the nitric oxide pathway reduced hyperemic response in healthy volunteers [46].

\section{Prognostic Vaules of CFR in Man}

Impaired CFR has been shown to confer great prognostic information for hard CV outcome, including all cause mortality, $\mathrm{CV}$ death and non-fatal MI. Independent of imaging modality used, the prognostic power of CFR appears to be consistent. In
post-MI setting, invasively assessed CFVR showed prognostic value in the "DEBATE" study. In such a setting, microvascular obstruction as well as infarct size may impact on CFVR alongside residual ischemia [47]. This concept has been extensively evaluated in patients with suspected coronary artery disease since they are undergoing ischemia testing based on clinical indication. In these patients, CFVR adds incremental prognostic values on top of wall motion analysis in terms of prediction of mortality and spontaneous CV events [33]. Interestingly, in the paper by Murthy et al., PET-CFR magnitude dependently predicted CV mortality across various levels of infarct size, ischemic burden and LV ejection fraction [48]. These data strongly supports the concept that CFR rather than just obstructive coronary artery disease contributes to $\mathrm{CV}$ vulnerability. In line with this, Murthy et al. showed that diabetic subjects without previous CAD but with impaired CFR had the same risk as non-diabetic patients with CAD [49]. Further, CFR showed great prognostic information in patients with dilated cardiomyopathy [50], which suggests that impaired CFR is an independent risk driving $\mathrm{CV}$ events in additional patient cohorts. In the context of post-infarct cardiac remodeling, impaired CFR is an independent predictor of adverse left ventricle remodeling [51]. The quantitative nature of CFR measurement is also reflected in its prognostic information, since it has also been shown that $\mathrm{CV}$ outcome is related to CFR in a magnitude dependent manner, that is the lower the CFR the worse the outcome and vice versa [48].

Transplant vasculopathy is a phenomenon of diffuse coronary artery disease for which traditional angiogram-based approaches cannot be used to follow the disease progression. In these patients, CFVR has been successfully used as a prognostic marker [52]. This further supports the concept that the integrative physiological assessment of the coronary functionality is of greater importance than only the luminology-based approaches.

\section{Effects of Established Interventions on CFR in Man}

That surgical by-pass or removal of hemodynamically significant obstructive epicardial lesions can improve CFR is of course a direct consequence of these procedures and follows the purpose and definition of a successful revascularization [53]. Other established CV treatments have also been shown to improve CFR through mode of action impacting on mechanisms controlling CFR (Table 1).

\section{LDL Apheresis}

Blood viscosity lowering approaches, for example: LDL apheresis, induce acute improvement of CFR in familiar hypercholesterolemic patients with extraordinarily high cholesterol levels [38]. 


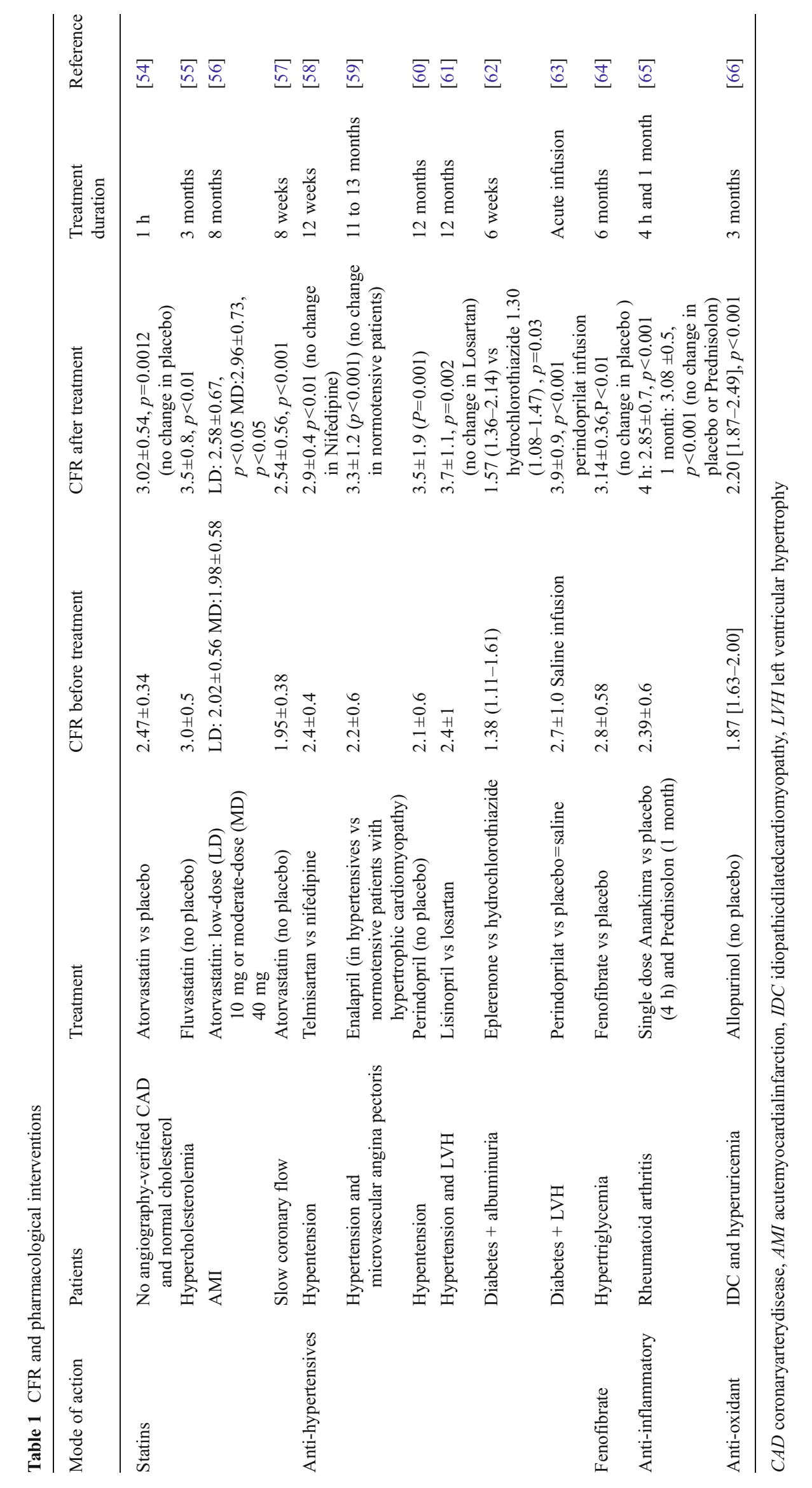




\section{Statins}

Statins have shown both acute effects on CFR probably through pleiotrophic effects but also in the medium-long term, which most likely is due to their LDL-lowering antiatherosclerotic effects.

\section{Anti-Hypertensives}

Anti-hypertensive drugs such as angiotensin-converting enzyme blocker or receptor blockers have shown beneficial effects on CFR through their effects on endothelium as well as anti-inflammatory properties. Decreased afterload following successful blood pressure normalization will also contribute to improvement of CFR due to reduced oxygen demand.

\section{Anti-Inflammatory}

In patients with increased systemic inflammation such as reumatoid artheritis, blockade of IL-1 pathway using anankinra immediately improved CFR and increased peripheral endothelial function as measured by flow-mediated forearm vasodilation as well as pulse wave velocity. Compared to prednisolon, which did not show any impact on the cardiovascular system in these patients, this treatment demonstrated sustained effects on these endpoints also at one month follow-up. The beneficial $\mathrm{CV}$ effects were also associated with a decrease in systemic inflammatory markers.

\section{Translational Aspects from a Drug Discovery Perspective}

Discovery and development of novel anti-atherosclerotic drugs to reduce cardiovascular events on top of standard of care is an area of high risk. Several difficulties have to be overcome in order to succeed with delivering a positive outcome in phase III trials. Traditionally, novel targets and compounds are validated in pre-clinical models of atherosclerosis with the primary readout being a reduction in plaque progression/size. Often such data provide the sole basis in terms of in vivo intervention data before investing in large clinical programs. For clinical proofof-concept, primary end-points have focused on plaque centric endpoints such as plaque volume, intima-media-thickness or plaque composition. Although these endpoints are associated with $\mathrm{CV}$ disease and $\mathrm{CV}$ events, limited information is available on how intervening with these endpoints affects $\mathrm{CV}$ benefit. This is not surprising since, atherosclerotic plaques are only one component contributing to the ischemic myocardial event in humans. Many additional biological mechanisms have been shown to play a role in triggering the event including microvascular dysfunction, endothelial dysfunction, systemic inflammation, vasospasm, thrombosis and angiogenesis [67-70]. By using a more integrative approach for proof-of- concept both pre-clinically and clinically, clinical development could be potentially de-risked.

To study the effects of novel anti-atherosclerotic compounds in animals within reasonable time frames, disease progression needs to be accelerated by genetic manipulation and/or feeding high-fat high-cholesterol containing diet. No single animal model available today mimics all aspects of this complex human disease and it is important to note in particular that no model reliably and reproducibly replicates the rupture and subsequent thrombotic occlusion of coronary arteries. As discussed previously, the pathophysiological events that occur at the level of the atherosclerotic plaques have been of great interest during the past few decades and also in animal studies targets which are involved in reducing plaque progression have been in focus for potential future interventions for reducing cardiovascular events. To gain confidence in potential novel therapies for reducing CV events, it is crucial that preclinical studies focus on the proper vascular bed and the relevant translational endpoints. Despite the prevalent use of mouse models of atherosclerosis, few have focused on the coronary arteries due to technical difficulties with studying these small arteries. Fortunately, due to recent advances with high-resolution imaging, it is now possible to perform morphological and functional imaging studies of cardiovascular systems in living mice [71-74]. This has dramatically increased the translational value of preclinical disease models and may provide guidance for dose selection and Proof of Principle studies in humans.

Despite the high heart rate in mouse, coronary flow velocity can be measured in a reproducible way using highresolution color Doppler ultrasound. This technique has now been applied in rodents and rabbits according to the human protocol (Fig. 3). The flow profiles in mouse left coronary artery (LCA) are strikingly human-like regarding amplitude, duration and systolic/diastolic distribution [71]. Due to its small size, little is known about coronary atherosclerosis and its functional implications in mice. By using ultrasound biomicroscopy the LCA can be visualized and the extent of atherosclerosis determined in a non-invasive, longitudinal way in living mice [75]. In a study performed in apoE/LDL receptor-deficient mice the percent wall thickness in the proximal LCA increased with age. Percent wall thickness was significantly associated with color Doppler echocardiography assessed mid- to distal coronary flow velocity ratios (Fig. 4). The extent of coronary atherosclerosis in the proximal LCA was confirmed by histological sections and correlated well with percent wall thickness and color Doppler echocardiography velocity ratios.

Our group pioneered the work to establish the TDE-CFVR approach in mice $[71,72,74,75]$ using high-resolution ultrasound. In addition to mid- to distal flow velocity ratio approach to determine LCA stenosis, CFVR can be determined in mice in a similar way as in humans using color Doppler 


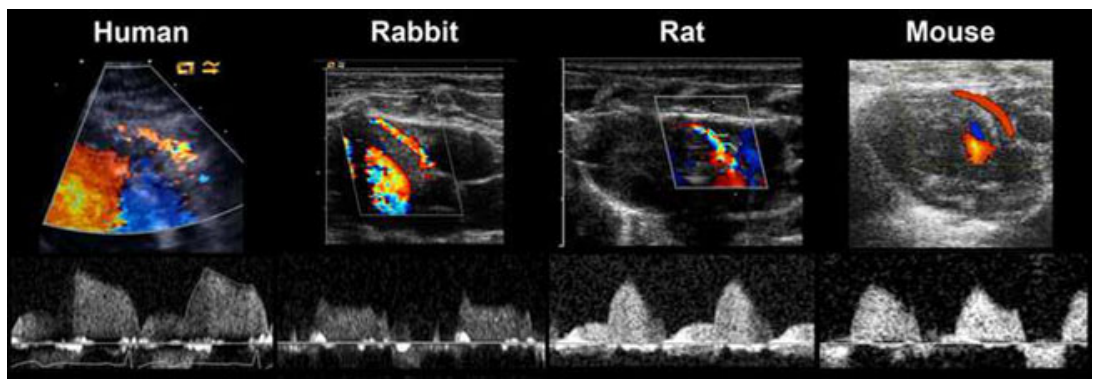

Fig. 3 Representative ultrasound imaging of the LCA in human, rabbit, rat and mouse. Upper panel: Color Doppler is used for identification of the LCA. In the present imaging windows, the LCA is shown as bright red-yellow streaks. White arrows indicate the site of the LCA where pulsed Doppler is used to measure coronary blood flow velocity. Lower

echocardiography. Hyperemia can be induced using adenosine at $160 \mu \mathrm{g} / \mathrm{kg} / \mathrm{ml}$ which is similar to the dose used in humans. This dose was shown to induce hyperemia without any apparent effects on systemic hemodynamics. Hypoxia is an alternate non-invasive means of inducing a similar increase in CFVR. In LDLR-deficient mice with coronary atherosclerosis, a correlation could be found between the extent of lumen narrowing and CFVR (Fig. 5) [72]. Although a correlation between coronary atherosclerosis and CFVR was demonstrated in mice it has also been shown that inflammation could impact on panel: corresponding pulsed wave Doppler signals for measurements of coronary blood flow velocity. Similar flow velocity patterns are evident between the species with minor flow signal during systole and a major flow signal during diastole. Flow velocity on $y$-axis (maximum velocity $100 \mathrm{~cm} / \mathrm{s}$ in these images), time on $x$-axis

CFVR, for example: CFVR is reduced following experimental coxsackie virus-induced myocarditis [73].

Although similar protocols are used to study CFVR in mice and humans, caution should be taken when comparing the absolute magnitude of changes since anesthesia is necessary in animal experiments and this has been shown to influence CFR in rodents [76]. Indeed, the most commonly used anesthetic agent isoflurane has been to shown to increase CFBV per se [77]. To assess coronary artery function in mice, CFVR is a good surrogate for CFR. In humans, a
Fig. 4 Plaque growth with increasing age in apoE/LDL double knock-out mice in the proximal $(\mathbf{a}, \mathbf{b}, \mathbf{c})$ and mid-LCA $(\mathbf{d}, \mathbf{e}, \mathbf{f})$ and the correlation between coronary artery percentage wall thickness as measured with histology and proximal to mid flow velocity ratio in the double knock-out mice of different age (g). Scale bar $=300 \mu \mathrm{m}$. A typical color Doppler image (h) showing site of proximal stenosis (white arrow) and stenosis-free segment in the more distal parts of the LCA (black arrow). Adapted from [75] with permission
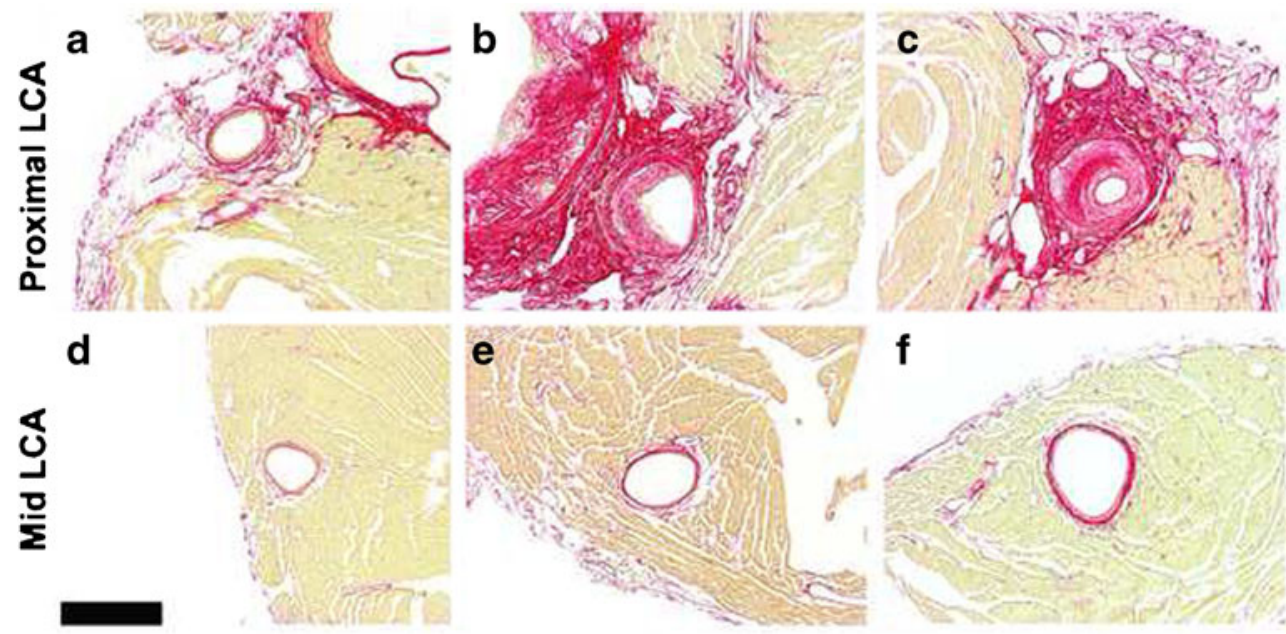

$10 w$

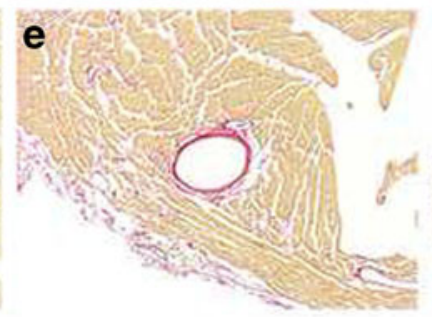

$40 w$
$80 w$

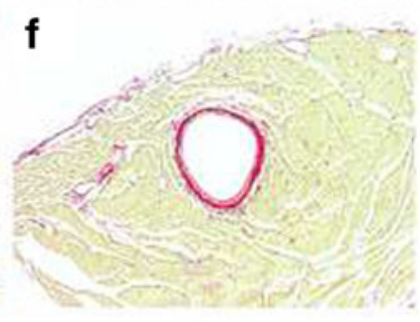

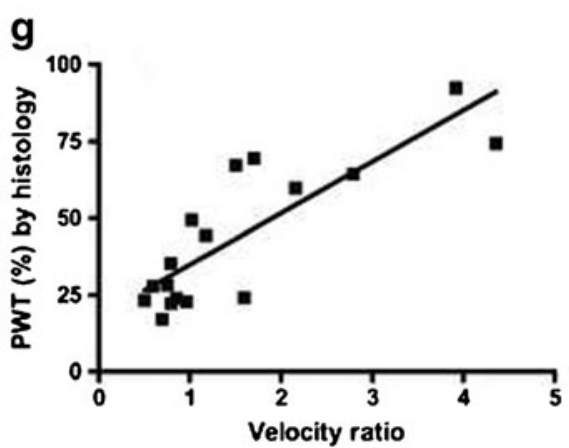

h

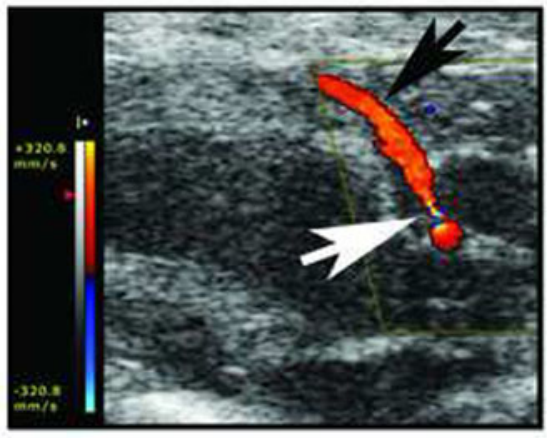



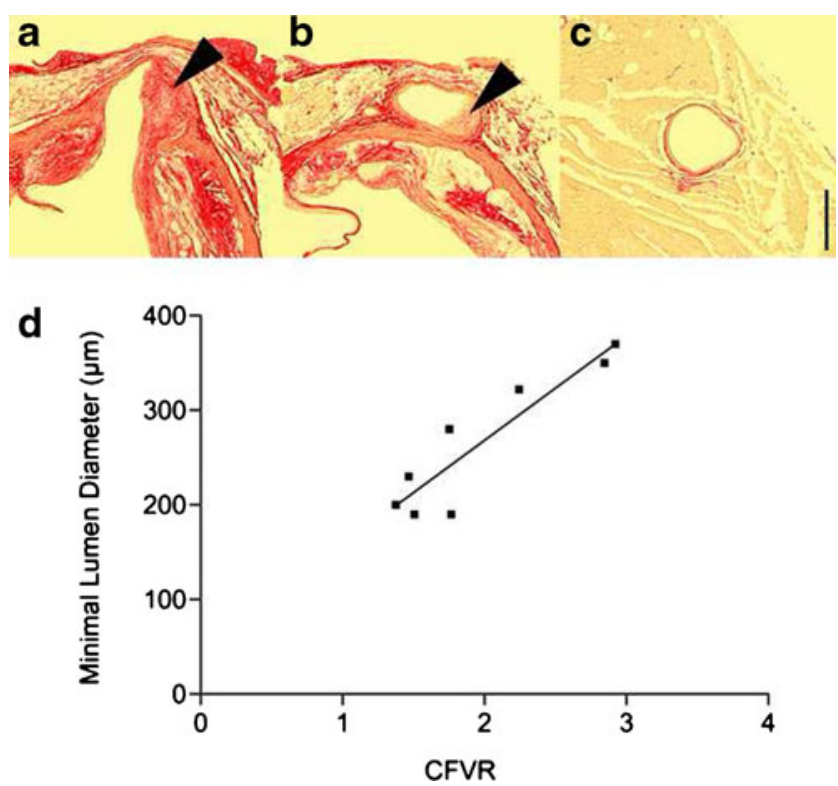

Fig. 5 Evidence of coronary artery atherosclerosis in the proximal segment $(\mathbf{a}, \mathbf{b})$ but not the mid-segment (c) of the left coronary artery in low-density lipoprotein receptor gene-deficient mice. A correlation was evident between minimal lumen diameter and CFVR (d) as imaged with high-resolution ultrasound. Arrowheads indicate coronary lesions. Scale bar $=200 \mu \mathrm{m}$. Adapted from [72] with permission

good correlation between CFVR and CFR has been demonstrated [78]. By measuring LCA lumen diameter and flow velocity simultaneously in mice, a good correlation between CFVR and CFR was evident. However, due to the larger intra- and inter-observer variability in CFR measures, CFVR is a more robust marker of coronary vascular health in mice [74] (Fig. 6).

\section{Effects of Interventions on CFR in Rodents}

The TDE-CFR approach has also been developed and applied in other species, for example: rat, to demonstrate effects of various interventions. We showed that spontaneous hypertensive rats improved their CFVR following voluntary endurance training through increased vascular anti-oxidant capacity [79]. Improvement of CFVR was also associated with improved vascular compliance and acetylcholine-mediated vasodilation in peripheral vascular beds [80] (Fig. 7).

Statins have become a standard therapy for $\mathrm{CV}$ patients and any novel therapy will need to demonstrate significant benefit on top of statins. Thus, back translation of statin effects to animal models is of fundamental importance for drug discovery and development. In addition to their cholesterol lowering effects, statins have been shown to retard the progression of atherosclerosis [81], improve endothelial function [82], reduce systemic inflammatory markers and reduce cardiovascular mortality [82-84]. The response to statins in animal models
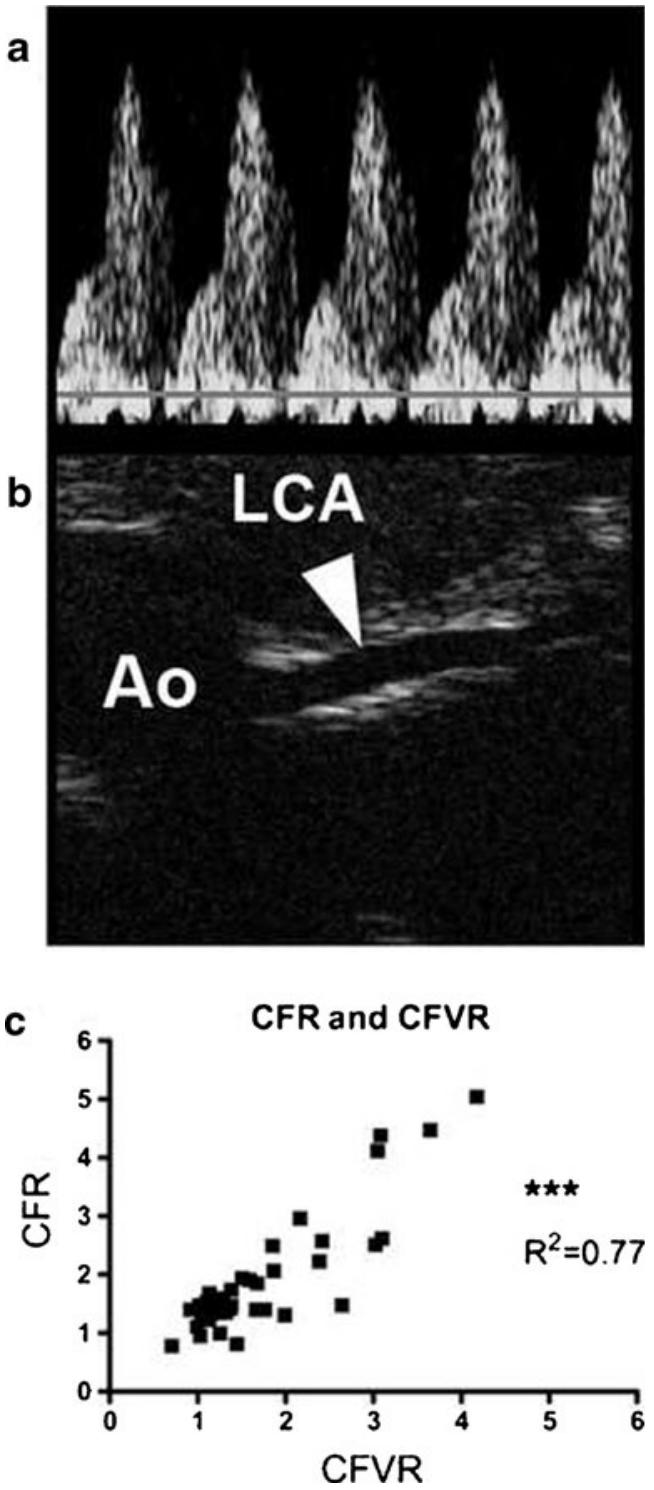

Fig. 6 CFR can be calculated from measurements of flow velocity measurements with pulsed Doppler (a) (flow velocity on the $y$-axis and time on the $x$-axis) and diameter measurements in B-MODE images (total image width $3 \mathrm{~mm}$ ) of the proximal to mid-segment (b) of the left coronary artery in vivo. Arrowhead indicate site where the LCA diameter was measured. There was a good correlation between CFVR and CFR (c). $A o=$ Aorta, $L C A=$ left coronary artery. Adapted from [74] with permission

varies with species, strain, gender, diet and protocol used. Although statins reduce plasma cholesterol and plaque area in some murine models, the exact mechanisms behind the cholesterol lowering effects are largely unknown. Statins have shown to reduce atherosclerosis in the apoE*3Leiden by changing lipoprotein profiles and total lipid levels $[85,86]$ in plasma. However, the so called "pleiotropic effects" may also play a significant role in this model [87]. In apoE- and LDLrdeficient mouse strains, statins have shown variable results on plasma cholesterol levels and plaque progression. ApoEdeficient mice on a mixed C57BL1/6 and 129SvJ (Taconic 
Fig. 7 Ultrasound imaging of the LCA in rat and improvement in CFVR with exercise. Upper panel (a-c): Color Doppler images from baseline (a), low dose (b), towards high dose of adenosine (c) with corresponding pulsed wave Doppler images (mid-panel:d-f). CFVR and adenosine doseresponse curves for voluntarily exercising spontaneous hypertensive rats (solid line) vs non-exercising controls (dashed line) (g). As evident, voluntary exercising rats had higher CFVR compared with controls after 6 weeks. ${ }^{* *} p<0.01$. Adapted from [79] with permission
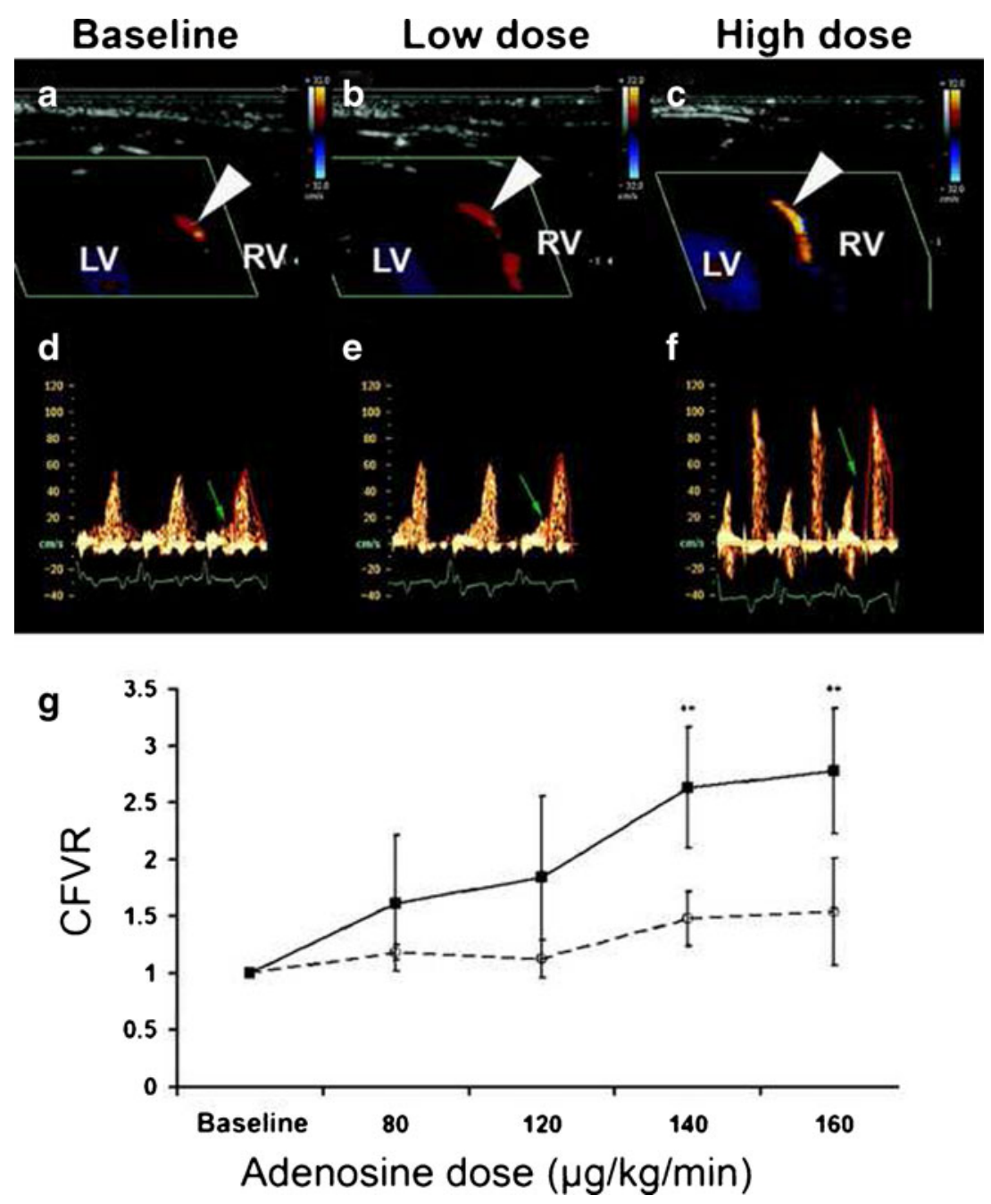

Denmark) background on a high-fat diet (21\% pork lard and $0.15 \%$ cholesterol) responded to rosuvastatin in a human like manner. Plasma Cholesterol levels were reduced on average by $20 \%$ during the 16-week study period [88]. In addition, brachiocephalic plaque area and the inflammatory serum biomarker serum amyloid-A (SAA) were significantly reduced at the end of the study suggesting additional effects similar to those observed in humans. Assessing coronary artery flow, calculated from UBM measured coronary diameter and color Doppler echocardiography flow velocity revealed an increase in hyperemic blood flow at the end of the study, again in line with findings in humans. Generating data in this animal model responding to statin therapy in a human-like way will improve our confidence in novel targets and facilitate future translational drug intervention studies in mice.

Grönros et al. used the TDE-CFVR approach to document effects of a novel arginase inhibitor, which may act by restoring normal nitric oxide balance in the vascular endothelium. In a rat model of type 2 diabetes, microvascular dysfunction as measured by CFVR was demonstrated relative to control rats.
Further, the arginase inhibitor succeeded to improve CFVR only in diabetic rats and not in control rats [89].

\section{CFR as a Translational Tool for Target Validation}

We and others have shown that CFR in vivo is reduced in late stage mouse atherosclerosis mouse models [72, 90], but also in the absence of coronary arthrosclerosis such as in models of diabetes [91], blood pressure overload induced heart failure [92] and myocarditis [73]. CFR can thus be measured in various disease models in vivo for exploration of disease mechanisms and might be used to validate novel drug targets.

5-Lipoxygenase (5-LO), five lipoxygenase activating protein (FLAP) and its products leukotrienes $\mathrm{B}_{4}\left(\mathrm{LTB}_{4}\right)$ and cysteinyl leukotrienes (cys LTs) have been linked to cardiovascular disease [93]. The ALOX5AP (FLAP) haplotype HapA has been associated with risk of MI [94] and levels of 5-LO, FLAP and $\mathrm{LTA}_{4} \mathrm{H}$ mRNA in human carotid plaques have been correlated with the occurrence of plaque instability 
[95]. In a phase II study, the 5-LO inhibitor, VIA-2291 reduced coronary plaque volume and new formation of rapidly growing coronary lesions in ACS patients following 6-months treatment [96]. These findings are in great agreement with many preclinical studies performed in animal models of atherosclerosis [97, 98].

To further explore the potential role of the 5-LO pathway in low degree subclinical inflammation and coronary vascular function, we carefully investigated CV function in 5-LOXdeficient mice (AstraZeneca Transgenic Centre, Mölndal, Sweden). We hypothesized that these mice could be protected from deleterious effects of lipopolysaccharide (LPS) challenge in a low-grade inflammatory, sub-acute setting.

Adenosine-induced CFVR, cardiac function and morphology were measured before and one week after LPS-challenge $(2 \mathrm{mg} / \mathrm{kg})$ in $5-\mathrm{LOX}^{-/}$and in back-crossed littermate C57BL/6 wild-type mice. Several cytokines and ex vivo aortic endothelial function were measured one week after LPS challenge to avoid acute sepsis-like condition. Cardiac function (not shown) and CFVR did not differ between the groups before the LPS challenge. However, one week after LPS challenge, CFVR was decreased in WT mice $(p<0.05)$ while no significant change was evident in 5-LOX ${ }^{-/-}$mice (Fig. 8). In vivo cardiac measurements were similar after LPS (not shown). Ex vivo aortic acetylcholine-mediated relaxation capacity in phenylephrine pre-contracted segments of the thoracic aorta was impaired in WT mice compared to $5-\mathrm{LOX}^{-1-}$ mice post LPS $(p<0.01)$. Levels of IL-10 were higher in the plasma of $5-\mathrm{LO}^{-/-}$mice compared to WT mice post LPS $(p<0.05)$.

Higher doses of LPS might induce septic shock with acute effects such as myocardial contractile dysfunction, drop in systemic blood pressure, vasoplegia, tissue hypoperfusion, microvessel injury and multiple organ injury [99], whilst low or moderate doses of LPS have been shown to induce endothelial dysfunction in experimental settings [100]. Our data seems to be consistent with the previous findings that 5-
LOX-deficient mice maintain blood pressure control better than control mice [101] and rats treated with a 5-LO inhibitor (Zileuton) showed reduced organ failure [99] following severe LPS endotoxemia. In addition to mediating inflammation [93, 102], direct vasoactive actions of the LTs have been frequently reported in both coronary [103] and aortic [101] arteries of several species. Thus, 5-LO metabolites seem to have both direct and indirect vasomodulating properties, especially in abnormal conditions, as observed in atherosclerotic arteries of humans [103]. Taken together, in addition to its anti-atherosclerotic effects, 5-LO pathway inhibition may also improve coronary vascular function in patients with systemic low-grade inflammation.

\section{Concluding Remarks}

In summary, accumulating evidence indicates that CFR may serve as a composite marker for coronary macro- and microvascular status, as well as systemic risk profile. Quantitative measurement of CFR provides us with an accurate prognostic tool to risk stratify patients as well as to follow disease progression and potential effects of intervention. Mechanistically, CFR is closely associated with many major pathoetiological factors driving residual risk in $\mathrm{CV}$ patients, such as epicardial vessel atherosclerosis burden and composition, left ventricle hypertrophy, vascular rarefaction, dyslipidemia, subclinical inflammation, endothelial dysfunction, etc. Establishment of the translational imaging techniques opens up exciting possibilities for deepened mechanistic understanding of this important pathophysiological phenomenon. Accumulated knowledge will hopefully accelerate development of novel therapeutic approaches targeting unexplored pathways to improve CFR and thereby further reduce $\mathrm{CV}$ mortality and morbidity. A translational approach and comprehensive understanding of the biology may potentially de-risk clinical development programs of
Fig. 8 CFVR in the LCA in vivo before (pre) and after (post) LPS challenge (a) and ex vivo aortic relaxation capacity with increasing doses of acetycholin (Ach) (b) in 5-LO KO mice after LPS challenge. ${ }^{*} p<0.05$, $* * p<0.01$

\section{Coronary flow velocity reserve}

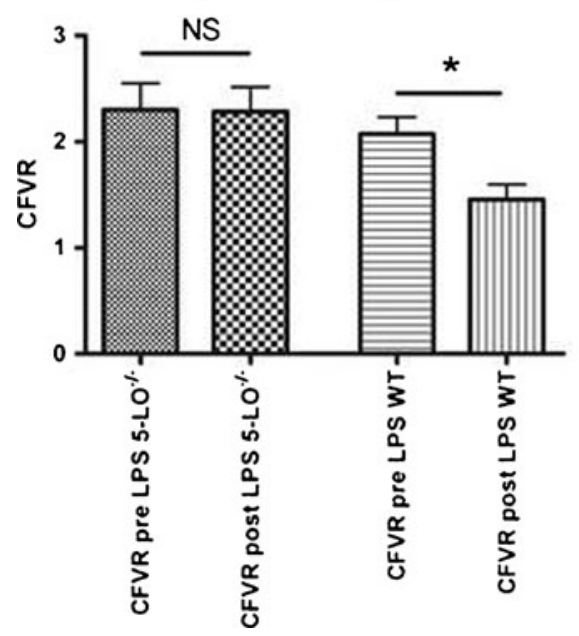

\section{ACh-mediated aortic relaxation}

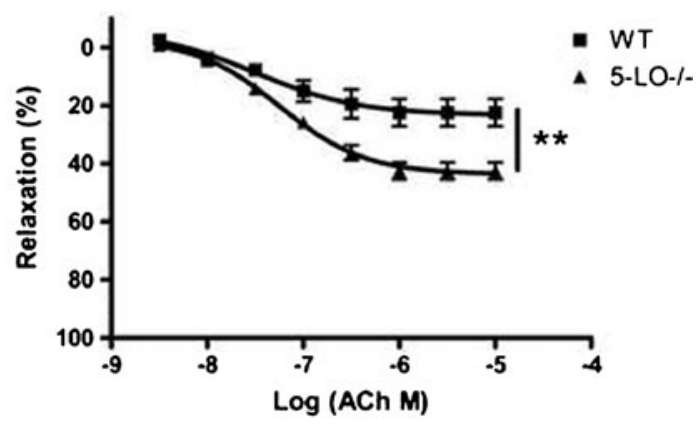


novel therapies. In addition to treatment correcting dyslipidemia and emerging drugs to reduce systemic inflammation, recent scientific progress within regenerative medicine may also in the not too distant future contribute to step-change therapies in terms of for example: regeneration of cardiomyocytes and coronary microvessels, and thereby restore a functional myocardium with well-dimensioned vascular bed.

Acknowledgment We are grateful to Dr. Carl Whatling and Mrs. Karin Mörup for excellent editorial assistance.

Conflict of Interest All authors are employers of AstraZeneca R\&D but have no conflicts to disclose in relation to this paper.

Open Access This article is distributed under the terms of the Creative Commons Attribution License which permits any use, distribution, and reproduction in any medium, provided the original author(s) and the source are credited.

\section{References}

1. de Fatima Marinho de Souza, M., Gawryszewski, V. P., Orduñez, P., Sanhueza, A., \& Espinal, M. A. (2012). Cardiovascular disease mortality in the Americas: current trends and disparities. Heart, 16(98), 1207-1212.

2. Gersh, B. J., Sliwa, K., Mayosi, B. M., \& Yusuf, S. (2010). Novel therapeutic concepts: the epidemic of cardiovascular disease in the developing world: global implications. European Heart Journal, 31(6), 642-648.

3. Dorbala, S., Di Carli, M. F., Beanlands, R. S., Merhige, M. E., Williams, B. A., Veledar, E., et al. (2013). Prognostic value of stress myocardial perfusion positron emission tomography: results from a multicenter observational registry. Journal of the American College of Cardiology, 61(2), 176-184.

4. Zellweger, M. J., Hachamovitch, R., Kang, X., Hayes, S. W., Friedman, J. D., Germano, G., et al. (2009). Threshold, incidence, and predictors of prognostically high-risk silent ischemia in asymptomatic patients without prior diagnosis of coronary artery disease. Journal of Nuclear Cardiology, 16(2), 193-200.

5. Kannel, W. B., \& Thomas, H. E., Jr. (1982). Sudden coronary death: the Framingham Study. Annuals of the New York Academy of Science, 382, 3-21.

6. Reichenbach, D. D., Moss, N. S., \& Meyer, E. (1977). Pathology of the heart in sudden cardiac death. The American Journal of Cardiology, 39(6), 865-872.

7. Spaulding, C. M., Joly, L. M., Rosenberg, A., Monchi, M., Weber, S. N., Dhainaut, J. F., et al. (1997). Immediate coronary angiography in survivors of out-of-hospital cardiac arrest. The New England Journal of Medicine, 336(23), 1629-1633.

8. De Bruyne, B., Pijls, N. H., Kalesan, B., Barbato, E., Tonino, P. A., Piroth, Z., et al. (2012). Fractional flow reserve-guided PCI versus medical therapy in stable coronary disease. The New England Journal of Medicine, 367(11), 991-1001.

9. Virchow, R. (1856). Thrombose und Embolie. Gefässentzündung und septische Infektion. Gesammelte Abhandlungen zur wissenschaftlichen Medicin (in German). Frankfurt am Main: Von Meidinger \& Sohn. pp. 219-732. Matzdorff AC, Bell WR (1998). Thrombosis and Embolie (1846-1856).

10. Lowe, G. D. (2003). Virchow's triad revisited: abnormal flow. Pathophysiology of Haemostasis and Thrombosis, 33(5-6), 455457.
11. Klabunde, R.E. (2011). Cardiovascular Physiology Concepts, Second Edition. Lippincott Williams \& Wilkins, Philadelphia

12. Gould, K. L., Kirkeeide, R. L., \& Buchi, M. (1990). Coronary flow reserve as a measure of stenosis severity. Journal of the American College of Cardiology, 15, 459-474.

13. Westerhof, N., Boer, C., Lamberts, R. R., \& Sipkema, P. (2006). Crosstalk between cardiac muscle and coronary vasculature. Physiological Reviews, 86, 1263-1308.

14. Gould, K. L., Lipscomb, K., \& Hamilton, G. W. (1974). Physiological basis for assessing critical coronary stenosis: instantaneous flow response and regional distribution during coronary hyperaemia as measures of coronary flow reserve. The American Journal of Cardiology, 33, 87-94.

15. Johnson, N. P., \& Gould, K. L. (2012). Integrating noninvasive absolute flow, coronary flow reserve, and ischemic thresholds into a comprehensive map of physiological severity. Journal of the American College of Cardiology: Cardiovascular Imaging, 5(4), 430-440.

16. Erdogan, D., Yucel, H., Uysal, B.A., Ersoy, I.H., Icli, A., Akcay, S. et al. (2013). Effects of prediabetes and diabetes on left ventricular and coronary microvascular functions. Metabolism. doi: 10.1016/j.metabol.2013.02.011

17. Dhawan, S. S., Corban, M. T., Nanjundappa, R. A., Eshtehardi, P., McDaniel, M. C., Kwarteng, C. A., et al. (2012). Coronary microvascular dysfunction is associated with higher frequency of thin-cap fibroatheroma. Atherosclerosis, 223(2), 384-388.

18. Johnson, N. P., Kirkeeide, R. L., \& Gould, K. L. (2012). Is discordance of coronary flow reserve and fractional flow reserve due to methodology or clinically relevant coronary pathophysiology? Journal of the American College of Cardiology: Cardiovascular Imaging, 5(2), 193-202.

19. Aarnoudse, W. H., Botman, K. J., \& Pijls, N. H. (2003). Falsenegative myocardial scintigraphy in balanced three-vessel disease, revealed by coronary pressure measurement. International Journal of Cardiovascular Interventions, 5(2), 67-71.

20. Aarnoudse, W., Van't Veer, M., Pijls, N. H., Ter Woorst, J., Vercauteren, S., Tonino, P., et al. (2007). Direct volumetric blood flow measurement in coronary arteries by thermodilution. Journal of the American College of Cardiology, 50(24), 2294-2304.

21. Doucette, J. W., Corl, P. D., Payne, H. M., Flynn, A. E., Goto, M., Nassi, M., et al. (1992). Validation of a Doppler guide wire for intravascular measurement of coronary artery flow velocity. Circulation, 85, 1899-1911.

22. Siebes, M., Verhoeff, B. J., Meuwissen, M., de Winter, R. J., Spaan, J. A., \& Piek, J. J. (2004). Single-wire pressure and flow velocity measurement to quantify coronary stenosis hemodynamics and effects of percutaneous interventions. Circulation, 109(6), 756-762.

23. Bergmann, S. R., Herrero, P., Markham, J., Weinheimer, C. J., \& Walsh, M. N. (1989). Noninvasive quantitation of myocardial blood flow in human subjects with oxygen-15-labeled water and positron emission tomography. Journal of the American College of Cardiology, 14, 639-652.

24. Gould, K. L., Goldstein, R. A., Mullani, N. A., et al. (1986). Noninvasive assessment of coronary stenoses by myocardial perfusion imaging during pharmacologic coronary vasodilation. VIII. Clinical feasibility of positron cardiac imaging without a cyclotron using generator produced rubidium-82. Journal of the American College of Cardiology, 7, 775-789.

25. Kajander, S., Joutsiniemi, E., Saraste, M., Pietilä, M., Ukkonen, H., \& Saraste, A. (2010). Cardiac positron emission tomography/computed tomography imaging accurately detects anatomically and functionally significant coronary artery disease. Circulation, 122(6), 603-613.

26. Choo, K.S., Hwangbo, L., Kim, J.H., Park, Y.H., Kim, J.S., Kim, J. (2013). Adenosine-stress low-dose single-scan CT myocardial perfusion imaging using a 128-slice dual-source CT: a comparison with fractional flow reserve. Acta Radiologica. DOI: 10.1177/ 0284185113475440 
27. Christian, T. F., Rettmann, D. W., Aletras, A. H., Liao, S. L., Taylor, J. L., \& Balaban, R. S. (2004). Absolute myocardial perfusion in canines measured by using dual-bolus first-pass MR imaging. Radiology, 232, 677-684.

28. Ay, T., Havaux, X., Van Camp, G., Campanelli, B., Gisellu, G., Pasquet, A., et al. (2001). Destruction of contrast microbubbles by ultrasound: effects on myocardial function, coronary perfusion pressure, and microvascular integrity. Circulation, 104, 461-466.

29. Hozumi, T., Yoshida, K., Ogata, Y., Akasaka, T., Asami, Y., Takagi, T., et al. (1998). Noninvasive assessment of significant left anterior descending coronary artery stenosis by coronary flow velocity reserve with transthoracic color Doppler echocardiography. Circulation, 97(16), 1557-1562.

30. Lethen, H. P., Tries, H., Kersting, S., \& Lambertz, H. (2003). Validation of noninvasive assessment of coronary flow velocity reserve in the right coronary artery. A comparison of transthoracic echocardiographic results with intracoronary Doppler flow wire measurements. European Heart Journal, 24(17), 1567-1575.

31. Murata, E., Hozumi, T., Matsumura, Y., Fujimoto, K., Sugioka, K., \& Takemoto, Y. (2006). Coronary flow velocity reserve measurement in three major coronary arteries using transthoracic Doppler echocardiography. Echocardiography, 23(4), 279-286.

32. Takeuchi, M., Lodato, J. A., Furlong, K. T., Lang, R. M., \& Yoshikawa, J. (2005). Feasibility of measuring coronary flow velocity and reserve in the left anterior descending coronary artery by transthoracic Doppler echocardiography in a relatively obese American population. Echocardiography, 22(3), 225-232.

33. Cortigiani, L., Rigo, F., Gherardi, S., Bovenzi, F., Molinaro, S., \& Picano, E. (2012). Coronary flow reserve during dipyridamole stress echocardiography predicts mortality. Journal of the American College of Cardiology: Cardiovascular Imaging, 5(11), 1079-1085.

34. Wittfeldt, A., Emanuelsson, H., Brandrup-Wognsen, G., van Giezen, J. J., Jonasson, J., Nylander, S., et al. (2013). Ticagrelor enhances adenosine-induced coronary vasodilatory responses in humans. Journal of the American College of Cardiology, 61(7), 723-727.

35. Canetti, M., Akhter, M. W., Lerman, A., Karaalp, I. S., Zell, J. A., \& Singh, H. (2003). Evaluation of myocardial blood flow reserve in patients with chronic congestive heart failure due to idiopathic dilated cardiomyopathy. The American Journal of Cardiology, 92, $1245-1249$.

36. Akasaka, T., Yoshida, K., Hozumi, T., Takagi, T., Kaji, S., Kawamoto, T., et al. (1997). Retinopathy identifies marked restriction of coronary flow reserve in patients with diabetes mellitus. Journal of the American College of Cardiology, 30, 935-941.

37. Tsagalou, E. P., Anastasiou-Nana, M., Agapitos, E., Gika, A., Drakos, S. G., Terrovitis, J. V., et al. (2008). Depressed coronary flow reserve is associated with decreased myocardial capillary density in patients with heart failure due to idiopathic dilated cardiomyopathy. Journal of the American College of Cardiology, 52(17), 1391-1398.

38. Tasaki, H. (2003). Low-density lipoprotein apheresis in the prevention of recurrent coronary heart disease: a review. Thererapeutic Apheresis and Dialysis, 7(4), 408-412.

39. Jeong, H. S., Hong, S. J., Park, J. H., Kim, J. H., Choi, S. C., Ahn, C. M., et al. (2012). Correlation between circulating angiogenic cell mobilizations and recovery of coronary flow reserve in patients with acute myocardial infarction. Circulation Journal, 76(5), 1213-1221.

40. Takahashi, T., Hiasa, Y., Ohara, Y., Miyazaki, S., Ogura, R., Miyajima, H., et al. (2007). Relation between neutrophil counts on admission, microvascular injury, and left ventricular functional recovery in patients with an anterior wall first acute myocardial infarction treated with primary coronary angioplasty. The American Journal of Cardiology, 100(1), 35-40.

41. Sarwar, N., Butterworth, A. S., Freitag, D. F., Gregson, J., Willeit, P., \& Gorman, D. N. (2012). Interleukin-6 receptor pathways in coronary heart disease: a collaborative meta-analysis of 82 studies. Lance, 379(9822), 1205-1213.

42. Vaccarino, V., Khan, D., Votaw, J., Faber, T., Veledar, E., \& Jones, D. P. (2011). Inflammation is related to coronary flow reserve detected by positron emission tomography in asymptomatic male twins. Journal of the American College of Cardiology, 57(11), 1271-1279.

43. Bonetti, P. O., Lerman, L. O., \& Lerman, A. (2003). Endothelial dysfunction: a marker of atherosclerotic risk. Arteriosclerosis, Thrombosis, and Vascular Biology, 23, 168-175.

44. Park, C. S., Youn, H. J., Kim, J. H., Cho, E. J., Jung, H. O., \& Jeon, H. K. (2006). Relation between peripheral vascular endothelial function and coronary flow reserve in patients with chest pain and normal coronary angiogram. International Journal of Cardiology, 113(1), 118-120.

45. Hägg, U., Wandt, B., Bergström, G., Volkmann, R., \& Gan, L. M. (2005). Physical exercise capacity is associated with coronary and peripheral vascular function in healthy young adults. American Journal of Physiology-Heart and Circulatory Physiology, 289(4), H1627-H1634.

46. Buus, N. H., Bøttcher, M., Hermansen, F., Sander, M., Nielsen, T. T., \& Mulvany, M. J. (2001). Influence of nitric oxide synthase and adrenergic inhibition on adenosine-induced myocardial hyperemia. Circulation, 104(19), 2305-2310.

47. Albertal, M., Voskuil, M., Piek, J. J., de Bruyne, B., Van Langenhove, G., Kay, P. I., et al. (2002). Doppler endpoints balloon angioplasty trial Europe (DEBATE) II study group. Coronary flow velocity reserve after percutaneous interventions is predictive of periprocedural outcome. Circulation, 105(13), 1573-1578.

48. Murthy, V. L., Naya, M., Foster, C. R., Hainer, J., Gaber, M., Di Carli, $\mathrm{G}$., et al. (2011). Improved cardiac risk assessment with noninvasive measures of coronary flow reserve. Circulation, 124(20), 2215-2224.

49. Murthy, V. L., Naya, M., Foster, C. R., Gaber, M., Hainer, J., Klein, J., et al. (2012). Association between coronary vascular dysfunction and cardiac mortality in patients with and without diabetes mellitus. Circulation, 126(15), 1858-1868.

50. Rigo, F., Gherardi, S., Galderisi, M., Pratali, L., Cortigiani, L., \& Sicari, R. (2006). The prognostic impact of coronary flow-reserve assessed by Doppler echocardiography in non-ischaemic dilated cardiomyopathy. European Heart Journal, 27(11), 1319-1323.

51. Meimoun, P., Boulanger, J., Luycx-Bore, A., Zemir, H., Elmkies, F., Malaquin, D., et al. (2010). Non-invasive coronary flow reserve after successful primary angioplasty for acute anterior myocardial infarction is an independent predictor of left ventricular adverse remodelling. European Journal of Echocardiography, 11(8), 711-718.

52. Tona, F., Caforio, A. L., Montisci, R., Gambino, A., Angelini, A., Ruscazio, M., et al. (2006). Coronary flow velocity pattern and coronary flow reserve by contrast-enhanced transthoracic echocardiography predict long-term outcome in heart transplantation. Circulation, 114(1 Suppl), I49-I55.

53. Fukui, T., Watanabe, H., Aikawa, M., Tsunoda, Y., Tabata, M., Takanashi, S., et al. (2011). Assessment of coronary flow velocity reserve by transthoracic Doppler echocardiography before and after coronary artery bypass grafting. The American Journal of Cardiology, 107(9), 1324-1328.

54. Hinoi, T., Matsuo, S., Tadehara, F., Tsujiyama, S., \& Yamakido, M. (2005). Acute effect of atorvastatin on coronary circulation measured by transthoracic Doppler echocardiography in patients without coronary artery disease by angiography. The American Journal of Cardiology, 96(1), 89-91.

55. Fujimoto, K., Hozumi, T., Watanabe, H., Shimada, K., Takeuchi, M., Sakanoue, Y., et al. (2004). Effect of fluvastatin therapy on coronary flow reserve in patients with hypercholesterolemia. The American Journal of Cardiology, 93(11), 1419-1421.

56. Hong, S. J., Choi, S. C., Kim, J. S., Shim, W. J., Park, S. M., Ahn, C. M., et al. (2010). Low-dose versus moderate-dose atorvastatin 
after acute myocardial infarction: 8-month effects on coronary flow reserve and angiogenic cell mobilisation. Heart, 96(10), 756-764.

57. Caliskan, M., Erdogan, D., Gullu, H., Topcu, S., Ciftci, O., Yildirir, A., et al. (2007). Effects of Atorvastatin on coronary flow reserve in patients with slow coronary flow reserve. Clinical Cardiology, 30(9), 475-479.

58. Hinoi, T., Tomohiro, Y., Kajiwara, S., Matsuo, S., Fujimoto, Y., Yamamoto, S., et al. (2008). Telmisartan, an angiotensin II type 1 receptor blocker, improves coronary microcirculation and insulin resistance among essential hypertensive patients without left ventricular hypertrophy. Hypertension Research, 31(4), 615-622.

59. Motz, W., \& Strauer, B. E. (1996). Improvement of coronary flow reserve after long-term therapy with enalapril. Hypertension, 27(5), 103-108.

60. Schwartzkopff, B., Brehm, M., Mundhenke, M., \& Strauer, B. (2000). Repair of coronary arterioles after treatment with peridonpril in hypertensive heart disease. Hypertension, 36(2), $220-225$.

61. Akinboboye, O. O., Chou, R. L., \& Bergmann, S. R. (2002). Augmentation of myocardial blood flow in hypertensive heart disease by angiotensin antagonist: a comparision of lisinopril and losartan. Journal of the American College of Cardiology, 40(4), 703-709.

62. Joffe, H. V., Kwong, R. Y., Gerhard-Herman, M. D., Rice, C., Feldman, K., \& Adler, G. K. (2007). Beneficial effects of eplerenone versus hydrochlorothiazide on coronary circulatory function in patients with diabetes mellitus. The Journal of Clinical Endocrinology and Metabolism, 92(7), 2552-2558.

63. Hesse, B., Meyer, C., Nielsen, F. S., Sato, A., Hove, J. D., Holm, S., et al. (2004). Myocardial perfusion in type 2 diabetes with left ventricular hypertrophy: normalisation by acute angiotensinconverting enzyme inhibition. European Journal of Nuclear Medicine and Molecular Imaging, 31(3), 362-368.

64. Wang, G., He, L., Liu, J., Yu, J., Feng, X., Li, F., et al. (2013). Coronary flow velocity reserve is improved by PPAR- $\alpha$ Agonist fenofibrate in patients with hypertriglyceridemia. Cardiovascular Therapeutics, 31(3), 161-167.

65. Ikonomidis, I., Lekakis, J. P., Nikolaou, M., Paraskevaidis, I., Andreadou, I., Kaplanoglou, T., et al. (2008). Inhibition of interleukin-1 by anakinra improves vascular and left ventricular function in patients with rheumatoid arthritis. Circulation, $117(20), 2662-2669$.

66. Erdeogan, D., Tayyar, S., Uysal, B. A., Icli, A., Karabacak, M., Ozaydin, M., et al. (2012). Effects of alopurinol on coronary microvascular and left ventricular function in patients with idiopathic dilated cardiomyopathy. Canadian Journal of Cardiology, 28(6), 721-727.

67. Marzilli, M., Merz, C. N., Boden, W. E., Bonow, R. O., Capozza, P. G., Chilian, W. M., et al. (2012). Obstructive coronary atherosclerosis and ischemic heart disease: an elusive link! Journal of the American College of Cardiology, 60(11), 951-956.

68. Sen, N., Afsar, B., Ozcan, F., Buyukkaya, E., Isleyen, A., Akcay, A. B., et al. (2013). The neutrophil to lymphocyte ratio was associated with impaired myocardial perfusion and long term adverse outcome in patients with ST-elevated myocardial infarction undergoing primary coronary intervention. Atherosclerosis, 228(1), 203-210.

69. Ohba, K., Sugiyama, S., Sumida, H., Nozaki, T., Matsubara, J., Matsuzawa, Y., et al. (2012). Microvascular coronary artery spasm presents distinctive clinical features with endothelial dysfunction as nonobstructive coronary artery disease. Journal of the American Heart Association, epub ahead of print.

70. Herrmann, J., Kaski, J. C., \& Lerman, A. (2012). Coronary microvascular dysfunction in the clinical setting: from mystery to reality. European Heart Journal, 33(22), 2771-2782b.
71. Gan, L. M., Wikström, J., Bergström, G., \& Wandt, B. (2004). Non-invasive imaging of coronary arteries in living mice using high-resolution echocardiography. Scandinavian Cardiovascular Journal, 38(2), 121-126.

72. Wikström, J., Grönros, J., Bergström, G., \& Gan, L. M. (2005). Functional and morphologic imaging of coronary atherosclerosis in living mice using high-resolution color doppler echocardiography and ultrasound biomicroscopy. Journal of the American College of Cardiology, 46(4), 720-727.

73. Saraste, A., Kyto, V., Saraste, M., Vuorinen, T., Hartiala, J., \& Saukko, P. (2006). Coronary flow reserve and heart failure in experimental coxsackie virus myocarditis. A transthoracic Doppler echocardiography study. American Journal of Physiology Heart and Circulatory Physiology, 291, H871-H875.

74. Wikström, J., Grönros, J., \& Gan, L. M. (2008). Adenosine induces dilation of epicardial coronary arteries in mice - relationship between coronary flow velocity reserve and coronary flow reserve in vivo using transthoracic echocardiography. Ultrasound in Medicine and Biology, 34(7), 1053-1062.

75. Grönros, J., Wikström, J., Hägg, U., Wandt, B., \& Gan, L. M. (2006). Proximal to middle left coronary artery flow velocity ratio, as assessed using color Doppler echocardiography, predicts coronary artery atherosclerosis in mice. Arteriosclererosis Thrombosis and Vascular Biology, 26, 1126-1131.

76. Croteau, E., Benard, F., Bentourkia, M. H., Rousseau, J., Paquette, M., \& Lecomte, R. (2004). Quantitative myocardial perfusion and coronary reserve in rats with $13 \mathrm{~N}$-ammonia and small animal PET:impact of anesthesia and pharmacologic stress agents. Journal of Nuclear Medicine, 45, 1924-1930.

77. Hartley, C. J., Reddy, A. K., Madala, S., Michael, L. H., Entman, M. L., \& Taffet, G. E. (2007). Effects of isofluorane on coronary blood flow velocity in young, old and apoE(-/-) mice measured by Doppler ultrasound. Ultrasound in Medicine and Biology, 33(4), 512-521.

78. Saraste, M., Kokskenvuo, J., Knuuti, J., Toikka, J., Laine, H., Niemi, P., et al. (2001). Coronary flow reserve: measurement with transthoracic Doppler echocardiography is reproducible and comparable with positron emission tomography. Clinical Physiology, 21(1), 114-122.

79. Hägg, U., Grönros, J., Wikström, J., Jonsdottir, I. H., Bergström, G., \& Gan, L. M. (2005). Voluntary physical exercise and coronary flow velocity reserve: a transthoracic colour Doppler echocardiography study in spontaneously hypertensive rats. Clinical Science, 109(3), 325-334.

80. Hägg, U., Andersson, I., Naylor, A. S., Grönros, J., Jonsdottir, I. H., Bergström, G., et al. (2004). Voluntary physical exerciseinduced vascular effects in spontaneously hypertensive rats. Clinical Science, 107(6), 571-581.

81. Ballantyne, C. M., Raichlen, J. S., Nicholls, S. J., Erbel, R., Tardif, J. C., Brener, S. J., et al. (2008). Effect of rosuvastatin therapy on coronary artery stenoses assessed by quantitative coronary angiography: a study to evaluate the effect of rosuvastatin on intravascular ultrasound-derived coronary atheroma burden. Circulation, 117(19), 2458-2466.

82. Blum, A., \& Shamburek, R. (2009). The pleiotropic effects of statin on endothelial function, vascular inflammation, immunomodulation and thrombogenesis. Atherosclerosis, 203(2), 325-330.

83. Ross, S. D., Allen, I. E., Connelly, J. E., Korenblat, B. M., Smith, M. E., Bishop, D., et al. (1999). Clinical outcomes in statin treatment trials: a meta-analysis. Archives of Internal Medicine, 159(15), 1793-1802.

84. Ridker, P. M., Danielson, E., Fonseca, F. A., Genest, J., Gotto, A. M., Jr., Kastelein, J. J., et al. (2008). Rosuvastatin to prevent vascular events in men and women with elevated C-reactive protein. The New England Journal of Medicine, 359(21), 2195-2207. 
85. de Haan, W., van der Hoogt, C. C., Westerterp, M., Hoekstra, M., Dallinga-Thie, G. M., Princen, H. M., et al. (2008). Atorvastatin increases HDL cholesterol by reducing CETP expression in cholesterol-fed APOE*3-Leiden CETP mice. Atherosclerosis, 197(1), 57-63.

86. van de Poll, S. W., Delsing, D. J., Jukema, J. W., Princen, H. M., Havekes, L. M., Puppels, G. J., et al. (2003). Effects of amlodipine, atorvastatin and combination of both on advanced atherosclerotic plaque in $\mathrm{APOE}^{*} 3$-Leiden transgenic mice. Journal of Molecular and Cellular Cardiology, 35(1), 109-118.

87. Kleemann, R., Princen, H. M., Emeis, J. J., Jukema, J. W., Fontijn, R. D., Horrevoets, A. J., et al. (2003). Rosuvastatin reduces atherosclerosis development beyond and independent of its plasma cholesterol-lowering effect in APOE*3-Leiden transgenic mice: evidence for antiinflammatory effects of rosuvastatin. Circulation, 108(11), 1368-1374.

88. Grönros, J., Wikström, J., Brandt-Eliasson, U., Forsberg, G. B., Behrendt, M., \& Hansson, G. M. (2008). Effect of Rosuvastatin on atherosclerosis and cardiovascular function in an ApoE-knockout mouse model of atherosclerosis. American Journal of PhysiologyHeart and Circulatory Physiology, 295, H2046-H2053.

89. Grönros, J., Jung, C., Lundberg, J. O., Cerrato, R., Ostenson, C. G., \& Pernow, J. (2011). Arginase inhibition restores in vivo coronary microvascular function in type 2 diabetic rats. American Journal of Physiology - Heart and Circulatory Physiology, 300(4), H1174-H1181.

90. Saraste, A., Kytö, V., Laitinen, I., Saraste, M., Leppänen, P., YläHerttuala, S., et al. (2008). Severe coronary artery stenoses and reduced coronary flow velocity reserve in atherosclerotic mouse model: Doppler echocardiography validation study. Atherosclerosis, 200(1), 89-94.

91. Katz, P. S., Trask, A. J., Souza-Smith, F. M., Hutchinson, K. R., Galantowicz, M. L., Lord, K. C., et al. (2011). Coronary arterioles in type 2 diabetic $(\mathrm{db} / \mathrm{db})$ mice undergo a distinct pattern of remodeling associated with decreased vessel stiffness. Basic Research in Cardiology, 106(6), 1123-1134.

92. Hartley, C. J., Reddy, A. K., Michael, L. H., Entman, M. L., Chintalagattu, V., Khakoo, A. Y., et al. (2010). Coronary flow reserve in mice: effects of age, coronary disease, and vascular loading. Conference Proceedings IEEE Engineering in Medicine and Biology Society, 3780-3783.

93. Samuelsson, B. (1983). Leukotrienes: mediators of immediate hypersensitivity reactions and inflammation. Science, 220, 568-575.
94. Helgadottir, A., Manolescu, A., Thorleifsson, G., et al. (2004). The gene encoding 5-lipoxygenase activating protein confers risk of myocardial infarction and stroke. Nature Genetics, 36, 233-239.

95. Qiu, H., Gabrielsen, A., Agardh, H. E., Wan, M., Wetterholm, A., Wong, C. H., et al. (2006). Expression of 5-lipoxygenase and leukotriene A4 hydrolase in human atherosclerotic lesions correlates with symptoms of plaque instability. Proceedings of the National Academy of Sciences, 103(21), 8161-8166.

96. Tardif, J. C., L'allier, P. L., Ibrahim, R., Grégoire, J. C., Nozza, A., Cossette, M., et al. (2010). Treatment with 5-lipoxygenase inhibitor VIA-2291 (Atreleuton) in patients with recent acute coronary syndrome. Circulation Cardiovascular Imaging, 3(3), 298-307.

97. Jawien, J., Gajda, M., Rudling, M., Mateuszuk, L., Olszanecki, R., Guzik, T. J., et al. (2006). Inhibition of five lipoxygenase activating protein (FLAP) by MK-886 decreases atherosclerosis in apoE/ LDLR-double knockout mice. European Journal of Clinical Investigation, 36(3), 141-146.

98. Cao, R. Y., St Amand, T., Gräbner, R., Habenicht, A. J., \& Funk, C. D. (2009). Genetic and pharmacological inhibition of the 5lipoxygenase/leukotriene pathway in atherosclerotic lesion development in ApoE deficient mice. Atherosclerosis, 203(2), 395-400.

99. Collin, M., Rossi, A., Cuzzocrea, S., Patel, N. S., Dipaola, R., Hadley, J., et al. (2004). Reduction of the multiple organ injury and dysfunction caused by endotoxemia in 5-lipoxygenase knockout mice and by the 5-lipoxygenase inhibitor zileuton. Journal of Leukocyte Biology, 76(5), 961-970.

100. Pleiner, J., Mittermayer, F., Schaller, G., MacAllister, R. J., \& Wolzt, M. (2002). High doses of vitamin C reverse escherichia coli endotoxin-induced hyporeactivity to acetylcholine in the human forearm. Circulation, 106, 1460-1464.

101. Lefebvre, B., Caron, F., Bessard, G., \& Stanke-Labesque, F. (2006). Effect of 5-lipoxygenase blockade on blood pressure and acetylcholine-evoked endothelium-dependent contraction in aorta from spontaneously hypertensive rats. Journal of Hypertension, 24, 85-93.

102. Dahlen, S. E., Bjork, J., Hedqvist, P., Arfors, K. E., Hammarström, S., Lindgren, J. A., et al. (1981). Leukotrienes promote plasma leakage and leukocyte adhesion in postcapillary venules: in vivo effects with relevance to the acute inflammatory response. Proceedings of the National Academy of Sciences, 78, 3887-3891.

103. Allen, S., Dashwood, M., Morrison, K., \& Yacoub, M. (1998). Differential leukotriene constrictor responses in human atherosclerotic coronary arteries. Circulation, 97, 2406-2413. 